\title{
SPEECH-LANGUAGE PATHOLOGY SERVICES DELIVERED BY TELEHEALTH IN A RURAL EDUCATIONAL SETTING: THE SCHOOL'S PERSPECTIVE
}

\author{
Natalie K Bradford BNurs, RN, MPH, PhD ${ }^{1,2}$, Liam J Caffery DipAppSci, BInfoTech, PhD ${ }^{1}$, Monica Taylor BSc, \\ MPH $^{1}$, Judith Meiklejohn BHlthSc (PubHlth), MAppSc (Research), GCDevPract ${ }^{1}$, Anthony C Smith BNurs, RN, \\ MEd, PhD ${ }^{1}$, Danette Langbecker BHIthSc(PubHlth), PhD ${ }^{1}$
}

${ }^{1}$ Centre for Online Health, The University of Queensland, Brisbane, Australia

${ }^{2}$ Institute of Health and Biomedical Innovation, Queensland University of Technology, Australia

\begin{abstract}
Introduction: Access to speech-language pathology services for children in rural and remote communities is often limited. Telehealth is increasingly used to provide these services to schools, demonstrating high satisfaction with both service providers and recipients, but the requirements for successful program implementation are as yet unclear. We aimed to explore the implementation requirements for a telehealth speech-language pathology service for children from the perspective of a rural school. Methods: A qualitative approach, supplemented by program activity data, was used to understand the experiences and perceptions of the benefits, limitations, enablers and barriers of a telehealth speechlanguage pathology program delivered to a school servicing approximately 400 children in a small rural town in the state of Queensland, Australia. Thematic analysis was conducted of transcripts of individual semi-structured interviews with nine school teaching staff and field notes of informal discussions regarding 85 speech-language pathology telehealth sessions $(\mathrm{n}=9$ children) during program establishment and implementation. Results: The speech-language pathology telehealth service was acceptable to teaching staff at the rural school, who cited improved access, the suitability of the technology for child engagement, and perceived effectiveness. Implementation issues were highlighted as critical to program success and scalability, particularly staff workload, technological issues, communication processes, and sustainability. Conclusion: School-based speech-language pathology services delivered via telehealth were perceived as a suitable way of increasing access for children by rural school staff. Future implementations of telehealth speech-language pathology programs should prospectively consider workload implications and develop strategies to communicate with and involve school staff.
\end{abstract}

Keywords: telerehabilitation; telehealth; rural health services; school health services; speech-language pathology

Bradford NK, et al. JISfTeH 2018;6:e21(1-8).

doi: 10.29086/JISfTeH.6.e20

Open access, published under Creative Commons Attribution 4.0 BY International Licence

\section{Introduction}

Approximately 5-13\% of children experience delayed speech and language development. ${ }^{1,2}$ Without appropriate interventions, delayed speech and language can impair academic and vocational opportunities and are associated with behavioural and emotional problems. ${ }^{3}$ Speech-language pathology services can prevent or minimise the consequences of these delays. ${ }^{4}$ Offering school-based services has a number of benefits, allowing speech-language pathologists to integrate within the education team, facilitating access for children, saving time and travel expenses for families, and providing a more inclusive education as children are not taken out of school..$^{5-7}$ However, the availability of speechlanguage pathology services is often limited in rural areas.

Telehealth is increasingly used to improve access to health services for rural and remote communities. ${ }^{8}$ In the United States, it is becoming more common to use telehealth to provide school-based speech-language pathology services, with high satisfaction achieved for both service providers and recipients. ${ }^{9-11}$ However, outside the US, speech-language pathology services via telehealth are not common. In Australia, there is high need for such services, but there is insufficient evidence to influence clinical practice or policy development. $^{3}$

In 2015, the Health-e-Regions project, a regional telehealth initiative, ${ }^{12}$ was expanded to include a schoolbased speech-language pathology program delivered by telehealth to a rural town. The overall aim of the project was to increase awareness and use of telehealth in a regional area through equipment installation, clinician education, partnerships and network creation, and media promotion. Before the telehealth speech-language pathology program was introduced, the selected school was serviced by a regionally-based speech-language pathologist covering several schools across a large regional area. Services at the 
school were limited to seven days per 10 week school term. This access was insufficient to service the number of children affected by delayed speech and language development, many of whom came from disadvantaged socio-economic backgrounds, with families who could not afford to access services privately.

There are few examples of school-based telehealth programs in Australia, despite its potential given Australia's size and dispersed population. One study found a telehealth speech-language pathology program delivered to rural schools in the state of New South Wales was acceptable and feasible from the perspective of parents. ${ }^{13}$ Another study showed a telehealth speech-language pathology program was acceptable to school executive and therapy assistants, but highlighted the need for a greater understanding of how to implement such programs. ${ }^{14}$ Understanding the perceptions and experiences of school staff members is integral to ensuring program sustainability and determining scalability to other schools. This study aimed to explore the implementation requirements of a telehealth speechlanguage pathology program from the perspectives of staff at a rural Australian school.

\section{Methods}

This study received ethics approval from both The Queensland Department of Education and Training and The University of Queensland Human Research Ethics Committee (ref: 2015001302).

Setting

The participating school was publically funded, servicing 400 children from Prep to Grade 10 (approximately ages 515) with 40 teaching staff. Located in the state of Queensland, Australia, approximately $300 \mathrm{~km}$ west of the state capital Brisbane, the town has an approximate population of 4,000 people. On a per capita basis, compared with Queensland as a whole, the town has more children, and more children classified as vulnerable due to a higher proportion of people receiving welfare benefits and a lower average income..$^{15,16}$ Beef Cattle and Sheep farming, and local government administration were the largest employers, but high rates of unemployment were reported.

\section{Speech-language pathology telehealth program}

The telehealth speech-language pathology program was developed in consultation with all stakeholders. Children exhibiting speech or language problems were assessed for suitability to participate in the program, based on identification of problems, and consent of the parent/guardian. Children were selected for inclusion in the program through discussion between the visiting schoolbased speech-language pathologist and the Head of Special Education (HoSE). The school's regular face-to-face speech-language program continued to run in parallel with the program. Selected children were scheduled to participate in weekly one-on-one therapy sessions over 12 weeks, in addition to the regular program. Final year undergraduate speech-language pathology students, supervised by a clinical educator, delivered therapy in individual sessions to the selected children via telehealth as part of their clinical practicum at The University of Queensland.

Individual speech-language pathology sessions were conducted via videoconference using two iPad Air devices (Apple, Cupertino, USA), utilising $\mathrm{eHAB}^{\circledR}$ telerehabilitation software (NeoRehab, Brisbane, Australia). Room-based videoconferencing equipment was also installed at the school as an alternative system. Training in equipment use and troubleshooting was provided to school staff coordinating the program.

\section{Study design and data generation}

An interpretive, qualitative approach using a social constructivist framework was used to explore experiences and perceptions of the program from the view of staff at the school. This framework acknowledges data analyses as coconstructions between the participants and the researcher, and allows that the results are an interpretation of the studied situation only. ${ }^{17}$

Two data generation strategies were used: 1) individual semi-structured interviews; and 2) field notes from informal discussions with school staff over the course of the study. Eligible participants were consenting teachers of children enrolled in the program and staff involved in special education (including delivery of the telehealth speechlanguage pathology program) at the school. Potential participants were identified by the School Principal and HoSE and independently invited to participate by the researchers.

An interview guide (Appendix 1) was developed based on the literature and elements from the Consolidated Framework for Implementation Research. ${ }^{18}$ Questions explored the perceived need for the program, and experiences and perceptions of program benefits, limitations, enablers and barriers, and flexibility was maintained to allow new lines of enquiry to be explored. To reduce recall bias, interviews were conducted during program implementation by a researcher (NB) not involved in program. Interviews were conducted by telephone, taking 12-27 minutes, and were audio-recorded and transcribed verbatim. The transcriptions were provided back to the interviewees for clarification and verification of content.

Program activity data (time, duration, and quality of each session) were collected prospectively by the coordinating teacher aide at the school for all planned sessions. The speech-language pathology clinic manager at The University of Queensland collected the same data, enabling confirmation by the two sources. These quantitative data are presented to provide context around the telehealth speechlanguage pathology service and its implementation.

\section{Data Analysis}

Transcripts were read multiple times and initial codes generated using an inductive approach. Comparison across 
and within transcripts enabled common and contrasting perspectives to be identified. Data were coded into categories and synthesised to generate broader themes. ${ }^{19}$ The analysis process consisted of systematically and iteratively checking and confirming the fit between the collected data, the conceptual analysis and interpretation of findings. Findings were discussed with reflexive awareness using a critical approach with all study authors, with consideration of alternative interpretations, groupings of categories and interrelations between categories. Consensus was achieved regarding the final coding structure and resultant themes. Illustrative quotes are provided to illuminate the themes and categories. Quantitative data were analysed descriptively.

\section{Results}

Eighty-five speech-language pathology sessions were delivered via telehealth over the 12 weeks of the program to nine students aged 5-13 years, receiving a median of 9 (range 3-12) sessions each (Table 1).

Ten staff members consented to participate in interviews about the program; due to participant illness, nine interviews were completed (Table 2). Most participants $(n=6)$ were teachers; the school principal, a teacher's aide, and a speechlanguage pathologist servicing schools in the region (each $\mathrm{n}=1$ ) also participated.

Two themes were identified from qualitative analysis of interviews and field notes: acceptability, and implementation issues and requirements.

\section{Acceptability}

This theme describes how participants saw the program as acceptable, encompassing improved access to services, the suitability of technology for child engagement, and perceived effectiveness.

\section{Improved access}

Participants reported very limited access to resources to support speech and language or speech-language pathology services prior to program implementation. Exposure to
Table 2. Characteristics of school staff participants $(n=9)$.

\begin{tabular}{|c|c|l|c|}
\hline Characteristics & $\mathrm{n}$ & Characteristics & $\mathrm{n}$ \\
\hline Gender & & Length of time at the school & \\
\hline Male & 2 & $<1$ year & 2 \\
\hline Female & 7 & $1-2$ years & 2 \\
\hline Age group (y) & & 3-5 years & 2 \\
\hline $18-24$ & 1 & 5+ years & 3 \\
\hline $25-34$ & 6 & $\begin{array}{l}\text { Experience with speech-language } \\
\text { problems (years) }\end{array}$ \\
\hline $35-44$ & 0 & 2 & 0-2 years \\
\hline $45-54$ & 2 & $3-10$ years & 3 \\
\hline & & 10+ years & 4 \\
\hline & &
\end{tabular}

written or spoken language through television, books, or regular interaction with other people was low for many socioeconomically disadvantaged families, for whom electricity was limited, books were uncommon and even travel into the local town was a novelty. Participants noted that the school's limited access to a speech-language pathologist meant few students received therapy. Accessing services privately was not possible for many parents due to cost and travel. Consequently, many children with delayed speech-language development did not receive treatment. School staff saw the program as a means of improving access to speech-language pathology services and promoting equity.

"A lot of our families live in poverty and if you spoke to them and asked them directly 'Is your child's speech worrying you', they would say 'yes'. They value it and when you are having a conversation with them, of course they love their children and they would like them to be as well-spoken as everybody else. They do value it. But when you live in poverty your priorities change from day to day and you have to make do. There are a lot of things that come before speech pathology, just basic needs being met." (Participant 2)

Suitability of technology for child engagement

Participants reported that technology facilitated child engagement with the program. Some staff were initially

Table 1. Activity data for the telehealth speech-language pathology program.

\begin{tabular}{|l|c|}
\hline Telehealth speech-language pathology sessions (n=92) & 85 \\
\hline Completed as scheduled & 7 \\
\hline Cancelled - child absent from school & 0 \\
\hline Cancelled - technical issues* & $39(7.5)$ \\
\hline Duration of session in minutes of sessions - mean (standard deviation) & $9(3-12)$ \\
\hline Number of sessions per child - median (range) & $3(3 \%)$ \\
\hline Technical issues with iPad* - n (\%) & $3(3 \%)$ \\
\hline Poor audio quality - no interruption to session & $11(13 \%)$ \\
\hline Poor video quality - no interruption to session & $11(13 \%)$ \\
\hline Problems with networks (iPad freezing/delay requiring restart) - session interrupted & $14(16 \%)$ \\
\hline Problems with licences, outdated software - session unable to be undertaken with iPad & $84(99 \%)$ \\
\hline Number of times room-based videoconferencing used because of iPad technical problems & \\
\hline Outcomes of session achieved as rated by telehealth speech-language pathology student/clinical educator & . \\
\hline
\end{tabular}

*Where technical issues occurred, alternative arrangements were made, e.g. using room-based videoconferencing system or delaying the session for a short time to allow problem resolution. 
concerned that children would not form therapeutic relationships over videoconferencing, but reported their fears were unfounded. Participants perceived that the children involved in the telehealth speech-language pathology program embraced the technology, and that therapeutic relationships were quickly established.

"It took me about four or so weeks to develop a relationship with him where he would trust me. I

don't know what's been happening up there, but he's developed that relationship far quicker [with the telehealth speech-language pathologist]... The kids out here will shut off if they don't trust you. "(Participant 2)

Several technological features were identified as facilitating child engagement. Participants perceived that children found telehealth sessions to be less intimidating than face-to-face sessions due to privacy, a time delay (due to a function of connectivity), distance, and receiving audio and visual feedback through a screen. The speech-language pathology providers' ability to develop rapport with the children was also attributed to their enthusiasm and youth.

"There's also a lovely delay there with technology which gives these children a bit of thinking time.... This is a perfect situation for speech because they can hear clearly, they can speak clearly; they can see the speech therapist's face very clearly. If she [the telehealth speech-language pathologist] is exaggerating something on the other end it's not as confronting as someone being in front of you asking you to do these - sometimes uncomfortable - exercises involving the mouth and the tongue and blowing and doing all those fun silly things... but he's not confronted at all and he loves technology." (Participant 5)

However, several teachers noted children were specifically chosen for the program, and telehealth may not be suitable for all children. One child was also withdrawn after three sessions as the child was not engaging as well as expected.

Perceived effectiveness

Participants perceived the program to have significant capacity to achieve improvements in speech-language development. Although the program was still underway at the time of interviews, participants perceived that benefits were already evident in terms of improved child confidence and fluency. Participants were unanimous in their support for the program.

"I was a little bit, not negative, but you're always a bit unsure about it. And I went to the first one and oh my goodness! This child who never speaks, who's extremely quiet, well he was talking, engaging, smiling, chattering away, and I thought - now this is worth it. We are seeing children here who usually are quite reserved or quite aggressive are changing, which is wonderful. (Participant 6)"

Implementation issues and requirement

This theme relates to program implementation, including workload, technological issues, communication, and sustainability.

Workload

Establishing and conducting the program was perceived to create an extra workload for school staff. Staff time was needed initially to develop agreements, obtain approvals, and obtain parental consent for child participation.

"The only issue I had was the initial setup is massive, so it was my job trying to coordinate it all, trying to get all the consent forms, everything signed. So calling in every parent, talking it through with them, so that was about an hour and a half each per parent, and then faxing everything through. It's a huge commitment. It's a lot of time and a lot of input. However, seeing the kids respond outweighs anything, because it's phenomenal. Yeah, because originally I was like 'Mmmm all this work, all this work, I hope it's worth it!', and it really has been fantastic." (Participant 6)

After establishment, the school redirected a teacher aide to coordinate the program, including escorting children to and from class, communicating with speech-language pathology providers, and preparing session resources. Most participants acknowledged the increased workload, however their level of concern depended upon how they were affected. Some teachers dismissed the extra workload due to its benefits for the children involved, while others not involved in program establishment described the workload as minimal. The workload required to establish the program was, however, identified as a barrier to increasing the program capacity and reach.

"There is no doubt there is a change in the workload, but I think the benefits outweigh that. Yes, unfortunately the teacher aide's been taken from a class and of course it's that teacher would tell you 'I'd like the teacher aide back', but fortunately it wasn't my teacher aide that was taken, so I'm saying the program is fabulous. (Participant 1)"

Technological issues

Many participants reported experiencing technological issues, particularly relating to Internet connectivity. However, as the room-based videoconferencing system and iPads used different networks for internet access (4G versus institutional uplink), the room-based system provided a backup in the case of connectivity issues (used on 14 occasions). Having plans to troubleshoot technological issues and the backup of the room-based system meant no sessions were cancelled because of technological issues. All participants were accepting of technological problems, reporting limited infrastructure and technological support as the reality of living in a rural location.

"I think probably the biggest concern is just a physical problem with technology out here. We quite often have a lot of difficulty with the Internet running slow or not running at all. We have quite a few blackouts as well from time to time. So I think the biggest barrier that we're facing with it 
will definitely be the technology itself and the limited access we have out here." (Participant 4)

"I know that telehealth is a great option for those rural areas, but then you run into the fact that because they're rural, technology options are difficult. When I was down there yesterday that it was really cloudy and rainy and that threw everything out of whack. (Participant 3$)$ "

\section{Communication}

Participants emphasised the importance of clear communication to incorporate the program into the school. Program establishment required negotiation between the school and speech-language pathology providers. Wellestablished lines of communication ensured clear expectations and proactive management of problems.

"You need a very clear process with expectations, otherwise things could just never happen. " (Participant 6)

Teachers appreciated being involved and having feedback provided to them. Teachers desired information to be provided through channels such as email if they could not be present at meetings. However, one teacher felt they had not received enough information to understand program benefits, which reduced their satisfaction with the program and led to feelings of frustration.

"Everyone's really interested in what it's all about. At three o'clock we have most of the teachers come down and we have our catch up thinking time and any sort of housework that we need to do and have some input from the [telehealth speech-language pathologist]." (Participant 5)

\section{Sustainability}

Program sustainability was a point of discussion in interviews. Participants reported 12 weeks was an appropriate length for the program and were hopeful it would continue. Some participants expressed concern regarding how children would be supported at the end of the program by existing services. One potential option identified to cover program costs into the future was the Department of Education and Training's funding schemes. These schemes allow schools to 'purchase' desired services, and a telehealth speech-language pathology service was viewed as worthy of this expenditure.

"The program's meant to run for I think it's 12 weeks or something roughly like that. I'm hoping we'll definitely see improvements then, but for long term sustainability you really need it to run six months. " (Participant 6)

\section{Discussion}

This study examined the implementation requirements of a telehealth speech-language pathology program from the perspective of staff from a school in rural Australia. Participants perceived the program improved access to speech-language pathology services, with potential for improvements in the children's speech-language development. Staff also reported the program increased workload and was resource intensive, requiring a teacher aide to be diverted from the classroom for program coordination. However, most staff believed the extra workload was worthwhile because of benefits to the children. The effect on workload may be more pronounced during the research element of such a program compared to normalised service.

This study complements the findings from other studies in similar contexts. Studies of telehealth speech-language pathology programs in rural New South Wales schools found it was feasible and acceptable from the perspective of parents, highlighting the need for regular communication to increase parental acceptability. ${ }^{13}$ Communication between all stakeholders was also recognised by school staff as essential for program success. ${ }^{14}$ In our study, lack of communication regarding the program negatively influenced the satisfaction of some teachers. These findings highlight the importance of stakeholder engagement and clear communication when implementing such a program.

Technology was perceived as both an enabler and a concern of the telehealth program. Teaching staff linked technology with children's enthusiasm and engagement. Similar findings have been reported elsewhere, ${ }^{4,20}$ supporting emerging evidence that telehealth does not negatively affect therapeutic relationships. ${ }^{21}$ Studies of telehealth programs in contexts outside speech-language pathology have also found children were highly motivated by use of technology. ${ }^{22,23}$ In our program, technology was used to bridge the distance barrier, however the suitability of this approach suggests telehealth-delivered services may be beneficial when a distance barrier does not exist, for example, with urban populations.

Participants also reported technological issues, particularly regarding Internet connectivity. Technological challenges relating to audio and video quality were highlighted as common issues in a recent systematic review of telehealth speech-language pathology studies. ${ }^{24}$ Such issues need to be considered when introducing a program reliant on technology, and backup and contingency plans developed.

Strengths and limitations

This study examined program delivery into a single school. The school was highly motivated and committed to program success, and the results reflect this positivity. The program was delivered by speech-pathology students under the supervision of clinical educators as part of an established student practicum clinic, and the perceptions and experiences of school staff may differ if the program was delivered outside of the student clinic environment. The study sample was small, however all teachers involved with the telehealth program except one were interviewed, and other participants included the school principal, a teacher's aide, and the speech-language pathologist servicing the school, providing a diverse range of perspectives to help address the research question. The findings of this study may not be applicable in 
wider contexts, however, naturalistic generalisation is possible.

\section{Conclusion}

Speech-language pathology services delivered by telehealth were perceived as a suitable way of increasing access for children by staff at a rural school. Workload, technological issues, communication and sustainability must be systematically addressed to enable widespread implementation of telerehabilitation services into rural schools.

Corresponding author:

Danette Langbecker

Centre for Online Health

The University of Queensland

Ground Floor, Building 33, Woolloongabba, QLD 4102

Princess Alexandra Hospital

Ph: +6173176 5356

Email: d.langbecker@uq.edu.au

Conflict of interest. The authors declare no conflicts of interest.

Acknowledgments: We wish to thank the staff, children and families who participated in and provided feedback for this program. We also wish to thank the speech-language pathology students who provided this service and the Clinical educators who supported them, as well as Professor Deborah Theodoros for her critical review of the manuscript. This research was conducted with the support of the Centre of Research Excellence in Telehealth funded by Australia's National Health and Medical Research Council (NHMRC, grant ID: APP1061183) and the Healthe-Regions program funded through Shell QGC. The contents of the published material are solely the responsibility of the individual authors and do not reflect the views of NHMRC or other funding agencies.

\section{Author contributions}

Natalie Bradford, Anthony Smith and Liam Caffery conceived and managed the study. Natalie Bradford collected the data. Danette Langbecker, Judith Meiklejohn and Monica Taylor completed data analysis and drafted the manuscript. All authors reviewed and approved the final version.

\section{References}

1. Nelson HD, Nygren P, Walker M, Panoscha R. Screening for speech and language delay in preschool children: systematic evidence review for the US Preventive Services Task Force. Pediatrics 2006;117(2):e298-e319.

2. McLeod S, Harrison LJ. Epidemiology of speech and language impairment in a nationally representative sample of 4-to 5-year-old children. J Speech Lang Hear Res 2009;52(5):1213-1229.

3. Taylor OD, Armfield NR, Dodrill P, Smith AC. A review of the efficacy and effectiveness of using telehealth for paediatric speech and language assessment. J Telemed Telecare 2014;20(7):405-412.

4. Tucker JK. Perspectives of speech-language pathologists on the use of telepractice in schools: the qualitative view. Int J Telerehabil 2012;4(2):47.

5. O'Callaghan AM, McAllister L, Wilson L. Barriers to accessing rural paediatric speech pathology services: health care consumers' perspectives. Aust J Rural Health 2005;13(3):162-171.

6. Ukrainetz TA, Fresquez EF. "What isn't language?": a qualitative study of the role of the school speechlanguage pathologist. Lang Speech Hear Serv Sch 2003;34(4):284-298.

7. Law J, Lindsay G, Peacey N, et al. Consultation as a model for providing speech and language therapy in schools: a panacea or one step too far? Child Lang Teach Ther 2002;18(2):145-163.

8. Moffatt JJ, Eley DS. The reported benefits of telehealth for rural Australians. Aust Health Rev 2010;34(3):276-281.

9. Grogan-Johnson S, Alvares R, Rowan L, Creaghead N. A pilot study comparing the effectiveness of speech language therapy provided by telemedicine with conventional on-site therapy. J Telemed Telecare 2010;16(3):134-139.

10. Lewis C, Packman A, Onslow M, Simpson JM, Jones M. A phase II trial of telehealth delivery of the Lidcombe Program of Early Stuttering Intervention. Am J Speech Lang Pathol 2008;17(2):139-149.

11. Crutchley S, Campbell M. TeleSpeech therapy pilot project: stakeholder satisfaction. Int $J$ Telerehabil 2010;2(1):23-30.

12. Smith AC, Caffery LJ, Saunders R, Bradford NK, Gray LC. Generating new telehealth services using a whole of community approach: experience in regional Queensland. J Telemed Telecare 2014;20(7):365-369.

13. Fairweather GC, Lincoln MA, Ramsden R. Speechlanguage pathology teletherapy in rural and remote educational settings: decreasing service inequities. Int J Speech Lang Pathol 2016;18(6):592-602.

14. Fairweather GC, Lincoln M, Ramsden R. Speechlanguage pathology telehealth in rural and remote schools: the experience of school executive and therapy assistants. Rural Remote Health 2017;17(3):4225. 
15. Croll J, Norton CJ, Gray LC, Bryett A, Smith AC.

Telehealth opportunities in regional Queensland: a scoping study. J Telemed Telecare 2012;18(8):451454.

16. Australian Bureau of Statistics. (2017). Australian Census 2016. Available at:

http://www.abs.gov.au/websitedbs/D3310114.nsf/Hom e/Census?OpenDocument\&ref=topBar accessed 26 September 2018

17. Charmaz K, Liska L. Qualitative interviewing and grounded theory analysis. In: Gubrium J, Holstein J, Marvasti A, McKinney K, editors. The SAGE Handbook of Interview Research: The Complexity of the Craft. Thousand Oaks, California: SAGE Publications; 2012;347-365.

18. Damschroder LJ, Aron DC, Keith RE, et al. Fostering implementation of health services research findings into practice: a consolidated framework for advancing implementation science. Implement Sci 2009;4:50.

19. Creswell JW, editor. Research design: Qualitative, quantitative, and mixed methods approaches. 4th ed. Los Angeles, California: SAGE Publications; 2013.

20. Lincoln M, Hines M, Fairweather C, Ramsden R, Martinovich J. Multiple stakeholder perspectives on teletherapy delivery of speech pathology services in rural schools: a preliminary, qualitative investigation. Int J Telerehabil 2014;6(2):65.

21. Freckmann A, Hines M, Lincoln M. Clinicians' perspectives of therapeutic alliance in face-to-face and telepractice speech-language pathology sessions. Int J Speech Lang Pathol 2017;19(3):287-296.

22. Macpherson CF, Linder LA, Ameringer S, et al. Feasibility and acceptability of an iPad application to explore symptom clusters in adolescents and young adults with cancer. Pediatr Blood Cancer 2014;61(11):1996-2003.

23. Palermo TM, Valenzuela D, Stork PP. A randomized trial of electronic versus paper pain diaries in children: impact on compliance, accuracy, and acceptability. Pain 2004;107(3):213-219.

24. Keck CS, Doarn CR. Telehealth technology applications in speech-language pathology. Telemed $J$ E Health 2014;20(7):653-659. 


\section{Appendix 1}

1. What are you hoping will be achieved with the introduction of the telehealth speech pathology program at [school]?

2. What are the problems associated with speech and language development at the school?

3. What are some of the challenges of delayed speech and language for:
a. Teaching staff
b. Students
c. Families

4. What are the benefits of the current services available to support speech and language development?

5. What are the limitations of the current services available to support speech and language development?

6. How do you think the program will help address these problems?
a. Do you think there will be benefits?
b. What time frames do you expect to see these benefits?

7. Who do you anticipate will benefit the most?
a. Speech therapy staff? Teaching staff? Students? Families?

8. Do you think telehealth is an acceptable alternative to face-to-face services?
a. Expand why $\mathrm{Y} / \mathrm{N}$

9. What concerns do you have regarding the program?

10. What do you think the limitations of the telehealth program will be?

11. Do you anticipate any problems or barriers with the program?

12. How well do you think telehealth services will be accepted by:
a. Other staff at the school
b. Students
c. Families
d. Wider community

13. Do you anticipate there will be a change in workload for staff?
a. Greater or lesser workload - why?
b. If higher workload - could this affect the success of the program?

14. Is there anything else that you think is important for us to know that we haven't talked about in the interview? 